\title{
Overview of Facial Plastic Surgery and Current Developments
}

\author{
Jessica Chuang ${ }^{1}$ Christian Barnes ${ }^{1,2}$ Brian J. F. Wong ${ }^{1,2}$ \\ ${ }^{1}$ Beckman Laser Institute and Medical Clinic, University of California \\ Irvine, Irvine, California \\ 2 Department of Otolaryngology-Head and Neck Surgery, University \\ Address for correspondence Brian J. F. Wong, MD, PhD, Beckman \\ Laser Institute and Medical Clinic, University of California Irvine, Irvine, \\ CA 92612 (e-mail: bjwong@uci.edu).
} of California Irvine, Irvine, California

Surg J 2016;2:e17-e28.

\author{
Abstract \\ Keywords \\ - facial plastic surgery \\ - skin rejuvenation \\ - rhinoplasty \\ - craniomaxillofacial \\ reconstruction \\ - injectable fillers \\ - facial reanimation \\ - 3D imaging and \\ printing \\ - stem cells \\ - wound healing
}

Facial plastic surgery is a multidisciplinary specialty largely driven by otolaryngology but includes oral maxillary surgery, dermatology, ophthalmology, and plastic surgery. It encompasses both reconstructive and cosmetic components. The scope of practice for facial plastic surgeons in the United States may include rhinoplasty, browlifts, blepharoplasty, facelifts, microvascular reconstruction of the head and neck, craniomaxillofacial trauma reconstruction, and correction of defects in the face after skin cancer resection. Facial plastic surgery also encompasses the use of injectable fillers, neural modulators (e.g., BOTOX Cosmetic, Allergan Pharmaceuticals, Westport, Ireland), lasers, and other devices aimed at rejuvenating skin. Facial plastic surgery is a constantly evolving field with continuing innovative advances in surgical techniques and cosmetic adjunctive technologies. This article aims to give an overview of the various procedures that encompass the field of facial plastic surgery and to highlight the recent advances and trends in procedures and surgical techniques.

The practice of modern facial plastic surgery began more than 100 years ago. ${ }^{1}$ Otolaryngologists who believed in treating physical defects that caused patients psychological distress, social, and/or economic disadvantages pioneered the creation of facial plastic surgery as a subspecialty of otolaryngology. In the beginning, aesthetic surgery was outside mainstream medicine, but Jacques Joseph first promoted the value of cosmetic surgery as a specialized field. ${ }^{1,2}$ Jacques Joseph is considered the founding father of modern facial plastic surgery, and he pioneered many of the earliest surgical aesthetic techniques that were later adopted and modified by fellow surgeons. ${ }^{2}$ Another seminal contributor was Sir Harold Gillies, a New Zealand otolaryngologist by training who first standardized rhinoplasty, skin grafts, and facial reconstruction as described in his 1920 book Plastic Surgery of the Face. ${ }^{3}$ He is often considered the founding father of plastic surgery. ${ }^{3-5}$ The creation of the American Academy of Facial Plastic and Reconstructive Surgery (AAFPRS) in 1964 officially marked the beginning of modern facial plastic surgery as a subspecialty

received

November 16, 2015

accepted

January 5, 2016
DOI http://dx.doi.org/ $10.1055 / \mathrm{s}-0036-1572360$. ISSN 2378-5128. of otolaryngology. ${ }^{6}$ Since then, facial plastic surgery societies have expanded globally to include the European Academy of Facial Plastic Surgery and the International Federation of Facial Plastic Societies, among others. ${ }^{7}$

As a clinical specialty, facial plastic surgery is generally divided into cosmetic and reconstructive procedures, although many surgeons have broad practices encompassing both. In general, the scopes of practice for the majority of facial plastic surgeons in the United States are focused on cosmetic procedures (e.g., rhinoplasty, browlifts, blepharoplasty, facelifts) and reconstruction of defects in the face after skin cancer resection. Most facial plastic surgeons also use injectable fillers, neural modulators, lasers, and other devices aimed at rejuvenating skin. Facial plastic surgeons who focus on skull base and craniomaxillofacial trauma or microvascular reconstruction usually practice in tertiary centers such as university hospitals.

Facial plastic surgery is technically considered a subspecialty of otolaryngology head and neck surgery, and surgeons are diplomats of the AAFPRS. Facial plastic surgeons complete
Copyright $\odot 2016$ by Thieme Medical Publishers, Inc., 333 Seventh Avenue, New York, NY 10001, USA. Tel: +1(212) 584-4662.
License terms

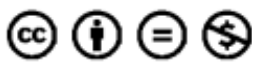


American Board of Medical Specialties-accredited residency training in otolaryngology as well as a 1- to 2-year facial plastic surgery fellowship. In contrast to general plastic surgeons, facial plastic surgeons focus on procedures and operations involving anatomy from the neck up. In reality, the specialty has significant overlap and crossover with general plastic surgery, oral maxillofacial surgery, ophthalmology, and dermatology.

Facial plastic surgery is a broad field of otolaryngology surgery that involves reconstructive and cosmetic techniques in addition to the use of biomaterials, lasers, and other adjunct materials to improve outcomes. This article is by no means comprehensive but gives an overview of the various procedures that encompass the field of facial plastic surgery, highlights recent advances and trends in interventions, and aims to identify the direction of future technologies and cosmetic agents.

\section{Cosmetic Surgery}

Facial cosmetic surgery focuses on improving patient facial appearance. Common surgical procedures include rhinoplasty, blepharoplasty (eyelid surgery), rhytidectomy (facelift), browlift, genioplasty (chin augmentation), otoplasty (ear repositioning), liposuction, and fat transfer. Many patients seek surgical treatment to reverse changes that occur with aging, such as loose skin, decreased tissue volume around the face and neck, crow's-feet at the corner of eyes, fine lines on the forehead, loss of jawline contour, sagging jowl, and double chin.

\section{Rhinoplasty}

Perhaps the most commonly performed and most difficult facial plastic surgery is rhinoplasty. It is performed to correct intrinsic and extrinsic nasal pathology, to modify unsatisfactory aesthetic appearance, to reduce airway obstruction (due to septal deviation, inferior turbinate hypertrophy, deviated/ fractured nasal bones, and narrow internal nasal valve area), and to reconstruct congenital nasal anomalies. ${ }^{8}$ During a rhinoplasty, the nasal skin, subcutaneous soft tissue, cartilaginous and bony framework, and mucous membrane lining are manipulated. ${ }^{9}$ The open rhinoplasty is differentiated from the endonasal rhinoplasty in that the incision is made in the columella (fleshy tip of the nose that separates the nares) in the open approach. ${ }^{9}$ The general principle of a rhinoplasty consists of a separation of the nasal skin and soft tissues from the osseocartilaginous nasal framework so that the framework can be reshaped to produce the desired nasal contours. Rhinoplasty is a technically challenging procedure that has complication rates from 4 to $18.8 \% .^{8}$ Postoperative scarring and edema as well as patient dissatisfaction can lead to revision surgery (secondary rhinoplasty).

Over the past 10 years, rhinoplasty surgery has trended toward using structural techniques that require cartilage tissue to reconstruct shape, bolster anatomic components, expand the airway, and establish appropriate aesthetic contour. ${ }^{10}$ Advances in this area include the broader use of cartilage for structural grafting. Traditionally, rib cartilage was used for only major reconstructive nasal operations, but more recently the number and type of grafts that are used in rhinoplasty have increased at least 10 -fold as rib graft use became more prevalent in even primary cosmetic rhinoplasty. ${ }^{11}$ Several new technological devices have evolved in recent years including polydioxanone foils to stabilize structural planes, ${ }^{12}$ ultrasonic devices to perform precise osteotomies, ${ }^{13}$ and the intranasal application of conventional high-speed powered instruments. ${ }^{14}$ Digital imaging has become an increasingly important element of rhinoplasty planning, evolving to become an essential component of the preoperative consultation. Three-dimensional (3-D) imaging systems along with 3-D image morphing technologies are now widely used by most surgeons, though there is no universally accepted software platform. ${ }^{15}$

\section{Facelift}

The facelift is another common procedure performed by facial plastic surgeons. When facelifts were first advocated over 100 years ago, the procedure itself involved making multiple incisions and pulling the skin on the face tighter. Now the traditional incision is made in front of the ear, extending up into the hairline and curving around the bottom of the lobule and then behind the ear. ${ }^{16,17}$ The skin is separated from the deeper tissues, and then the deeper tissues are tightened with sutures. In the final step, the skin is redraped with the excess skin removed. ${ }^{16,18}$

Advancements in facelift procedures have been largely driven by the demands and desires of patients. Contemporary patients are looking for minimally invasive procedures with little to no postoperative downtime. Treatment of the aging face has been profoundly impacted by the rise of socalled lunchtime facelift-type operations. ${ }^{19-21}$ In the mid1990s, facelifts and rejuvenation operations were becoming increasingly technically demanding and risky due to exposure of the facial nerve branches and extensive soft tissue dissections. $^{22}$ These complex procedures yielded superb outcomes in expert hands; however, often patients operated on by less-experienced surgeons experienced prolonged postoperative edema, sensory or motor nerve injury, and facial asymmetry. ${ }^{22,23}$ Today there are many facelift approaches, such as the deep plane facelift, composite facelift (which involves repositioning and fixation of the orbicularis oculi muscle), midfacelift, minifacelift, thread lift, periosteal facelift, skin-only facelift, and minimal access cranial suspension lift. ${ }^{22}$ Each can achieve outstanding outcomes but largely depend upon surgical skill and the anatomic variations from patient to patient. In the 2000s, there was a rise in less invasive procedures, which could be performed under local anesthesia with oral benzodiazepines or with moderate sedation. ${ }^{24}$ Overall numbers of facelifts increased because of the marketing of many nationally branded facelift-rejuvenation companies. According to the American Society for Aesthetic Surgery, the number of facelifts performed in 2014 grew by $27.7 \%$ compared with $1997 .{ }^{25}$ A major trend in recent years is the combination of facelift operations with autologous fat transfer, which also addresses the volume loss that occurs with aging. ${ }^{26}$ 


\section{Blepharoplasty}

Another popular facial procedure is blepharoplasty, or eyelid surgery. Blepharoplasty involves the excision of excessive eyelid skin and/or removal of orbital fat to treat dermatochalasis (aging-related changes in the periorbital structures) and blepharochalasis (excessive papery thin skin). ${ }^{27}$ The action of gravity on periorbital structures, decreased strength in periorbital muscles, sun damage, and changes in skin composition may cause aesthetically displeasing changes referred to in the vernacular as "droopy eyelids," "tired eyes," or "bags under the eyes." The traditional approach for lower blepharoplasty is through a subciliary incision with a raised skin and muscle flap, followed by identification and correction of herniated medial, middle, and lateral fat. ${ }^{27}$

The skin pinch blepharoplasty is the easiest to perform. In this technique, only excess skin is excised through a subciliary approach; it avoids a heavy skin-muscle flap, which can create worrisome vertical traction and swelling in the periorbital tissues. ${ }^{28}$ The pinch blepharoplasty of the lower lid also foregoes violation of the orbicularis muscle and the orbital septum to avoid nerve injury and to decrease scarring. ${ }^{28}$ This approach allows more wrinkled, thin skin to be safely removed and an aesthetic eyelid posture to be maintained. Both upper and lower lid blepharoplasties are often performed under local anesthesia or moderate sedation. Of note, blepharoplasty is also performed to correct lid ptosis, which results from several causes. ${ }^{29}$ The most common cause is levator palpebrae superioris attenuation. ${ }^{30}$

\section{Forehead Lifts and Browlifts}

Forehead lifts or browlifts also are a large part of a facial plastic surgery practice. This procedure is relatively straightforward in terms of its classical approach where excess skin is resected and the forehead skin is repositioned superiorly. ${ }^{31}$ The incisions are placed along a coronal line within the hair-bearing scalp if the frontal hairline is low. A hairline (trichial or trichophytic) incision is used in patients with a high hairline. ${ }^{32}$ These two approaches are most commonly used in women. In men, a third option is the midbrowlift where an incision is made in a deep brow furrow, and a fusiform ellipse of skin is resected. ${ }^{32}$ A direct browlift, where the incision is made at the upper margin of the eyebrows, is rarely performed. Both midand direct browlifts may leave a visible scar, and they are more commonly used for functional brow surgery in patients who have significant brow ptosis contributing to a mechanical visual field defect. The newest approach is endoscopic surgery where several small incisions are placed behind the hairline and an endoscope is used for visualization during elevation of the forehead skin. With the endoscope under the forehead flap, the surgeon releases soft tissue from the arcus marginalis and temporal line of fusion, allowing redraping and fixation of the skin more cephalically. ${ }^{33,34}$ The results are less dramatic, but it is an outstanding approach in the younger patient who seeks more natural and less-defined changes.

\section{Hair Restoration}

Hair loss is a major concern for many, and hair transplantation advancements continue to provide a good option for correc- tion. ${ }^{35}$ Numerous physicians across a dozen specialties perform these procedures. Historically, punch grafts of the scalp were used in hair transplantation, but these created a highly unnatural look over the recipient area with multiple scars at the donor site. The concept of minigrafts and micrografts was advocated in the late 1970 s. $^{36}$ Scalp flap surgery was relatively popular during the 1980s, but in 1984 Headington pioneered the concept of follicular unit transplantation. ${ }^{37}$ Follicular unit transplantation is now the gold standard of hair restoration. It involves individual hair follicles or small groups of two to four follicles to be extracted and transplanted. It creates the most natural outcomes. ${ }^{35}$

Robotic surgery has definitely made advances across multiple surgery specialties and is now being used to automate follicular unit harvest and transplantation. ${ }^{38,39}$ Semiautonomous robotic systems harvest, sort, and process individual single hair grafts or multiple hair grafts. ${ }^{40}$ It remains to be seen whether these systems are economically viable related to conventional methods, which required meticulous sectioning of follicular units by teams of technicians.

\section{Nonsurgical Cosmetic Procedures}

A large evolving part of facial plastic surgery involves using techniques such as chemical peels, lasers, and various injectable substances to produce improved facial aesthetics. In comparison with most cosmetic surgery, these office-based procedures have a much-reduced recovery period.

\section{Chemical Peels}

Examples of chemical peel agents include glycol acid, trichloroacetic acid, and phenol (listed from mildest to strongest). ${ }^{41,42}$ During a chemical peel, the agent penetrates through the epidermis into the first layer of the dermis. Different agents have different depths of penetration and are divided into four histologic grades. ${ }^{43}$ The chemical agent causes destruction at various depths of the skin and stimulates skin regenerative pathways in the dermis that are not well understood. ${ }^{44}$

\section{Dermabrasion}

Dermabrasion is another technique used to smooth deeper scars and wrinkles. This technique is performed under a local anesthetic and/or a freezing agent. A high-speed rotating brush, sandpaper, or similar abrasive device is used to remove the top layer of the skin. ${ }^{45}$ This technique may be applied to individual blemishes or large areas of the face.

\section{Lasers}

Lasers are used to correct facial rhytides, scarring, photodamaged skin, and other signs of aging. Laser treatments cause little to no bleeding and induce minimal trauma to the surrounding skin. The technology allows for precise control of ablation depth. There are two types of laser therapy: ablative and nonablative.

Ablative lasers vaporize the superficial layers of the skin by heating the dermis to stimulate new collagen production by fibroblasts. Of the ablative lasers, there are two laser 
wavelengths in common use: pulsed carbon dioxide $\left(\mathrm{CO}_{2}\right)$ and erbium:yttrium-aluminum-garnet (Er:YAG). On average $\mathrm{CO}_{2}$ systems ablate 20 to $60 \mu \mathrm{m}$ of tissue with the initial pass, and the residual thermal damage extends to a depth of 20 to $100 \mu \mathrm{m}$ after multiple passes. ${ }^{46}$ The Er:YAG pulse laser systems vaporize 2 to $5 \mu \mathrm{m}$ of tissue per pass and leave behind a 20 - to $50-\mu \mathrm{m}$ zone of residual thermal damage. ${ }^{46}$ Thus erbium laser systems can be more finely tuned than $\mathrm{CO}_{2}$ systems and are useful for precise, finely adjusted, light to medium ablations. $\mathrm{CO}_{2}$ systems are more efficient for deep ablations.

Currently, novel systems are being developed to deliver simultaneous irradiation from combined Er:YAG laser and $\mathrm{CO}_{2}$ laser, variable-pulse Er:YAG, and dual ablation/coagulation Er:YAG. ${ }^{47,48}$ These new systems aim to achieve a significant degree of clinical improvement with less skin wounding to produce granulation tissue and fibroplasia but with thin zones of thermal damage. ${ }^{47}$ Some complications of ablative lasers include pain, edema, persistent erythema, infections, postinflammatory hyperpigmentation, and hypopigmentation. ${ }^{46}$

Nonablative lasers do not cause superficial injury to the epidermis but instead only stimulate collagen growth by creating focal thermal injury within the dermis. ${ }^{49,50}$ The Qswitched neodymium:yttrium aluminum garnet laser is especially useful in the treatment of periocular and perioral rhytides. Some other nonablative lasers include diode lasers, pulsed-dye lasers, and intense pulsed nonlaser light sources. ${ }^{49,51}$ Much research remains to be performed to better understand the laser-tissue interaction caused by nonablative lasers.

Finally, one of the biggest advances within the past 10 years is the development of spatially selective heating of tissue or fractional photothermolysis. The concept consists of thermal injury in full-thickness columns of controlled depth and width (microthermal zones), leaving the areas of untreated skin between them, which enables rapid tissue proliferation to repair the damaged areas. ${ }^{52}$ Fractional photothermolysis causes deep dermal damage that triggers collagen synthesis and remodeling while causing minimal epidermal damage. ${ }^{49}$ There are both fractional nonablative lasers and fractional ablative lasers. In general, the obtained therapeutic results of fractional nonablative lasers are better than those of nonablative lasers but are still inferior to traditional ablative resurfacing.

Fractional ablative lasers combine the principles of classic ablative techniques and fractional photothermolysis. The laser beam of ablative fractional lasers causes microscopic treatment zones consisting of central tiny ablative foci (microscopic ablation zones), surrounded by a thin necrotic zone encased by a coagulation zone (microscopic coagulation zone). ${ }^{49,53-55}$ Between the microscopic treatment zones, are areas of untreated skin ensure rapid healing. Re-epithelialization occurs within 48 hours with extrusion of the necrotic tissue with minimal inflammatory reaction. The postoperative erythema usually resolves in 7 days. ${ }^{49}$ The main advantage of fractional ablative resurfacing is its low risk for side effects and complications. Fractional laser thera- py was a great revolution in the field of laser skin resurfacing, and more laser devices are currently being developed and commercialized.

\section{Evolving Paradigm}

One of the most important changes in facial rejuvenation has been a shift from a two-dimensional focus on hyperdynamic facial lines and the immobilization of corresponding muscles to an increased understanding and appreciation of the three-dimensional aspects of facial aging, in particular the loss of volume. ${ }^{56}$ Facial rejuvenation now encompasses areas of movement control, recontouring, and volume restoration using multiple modalities. In conjunction with the recent trend toward minimally invasive cosmetic improvements in facial rejuvenation, clinicians are now using combinations of neuromodulators (distinct serotypes outlined below) with dermal fillers such as hyaluronic acid to address facial rejuvenation and to increase the longevity of the outcomes. ${ }^{57}$ Botulinum toxin remains a popular neurotoxin used to paralyze muscles to treat wrinkles caused by muscle activity. Injectable fillers are used to replace lost volume in the face and are available in increasing varieties. The most widely used filler products are autologous fat, collagens, hyaluronic acid, and synthetic polymers. ${ }^{56,58}$

\section{Fat Grafting}

Complementary fat grafting took hold broadly across the specialty as years of evidence largely driven by the work of many surgeons and dermatologists demonstrated the efficacy of the manual liposuction of fat and precise injection of small aliquots of this tissue into the regions surrounding the midface, orbit, temporal fossa, neck and other regions. Fat grafting is an essential component of many individuals' facelifts now, and there is much discussion and debate about whether mesenchymal stem cells are transferred in this process as well. ${ }^{59}$ Fat grafting can be performed using local anesthetic or moderate sedation. One issue with autologous fat grafting is the variability of graft survival (10 to $80 \%$ ), but there is continued research in improving fat transplant survival. ${ }^{60}$ Some techniques include pharmacologic manipulation of grafts with insulin-like growth factor, basic fibroblast growth factor, selective $\beta-1$ blocker, and platelet-rich fibrin matrix to enhance the survival of lipografts. ${ }^{61,62}$ The regulatory environment concerning these modifications is quite complex.

\section{Dermal Fillers}

Replacing lost or misplaced fat pads with dermal fillers is one important approach to recontouring the aging face as well as to treating scars and rhytides. The U.S. Food and Drug Administration (FDA)-approved temporary fillers consist of collagen, hyaluronic acid, calcium hydroxylapatite (CaHA), and poly-L-lactic acid (PLLA). ${ }^{58}$ The only FDA-approved permanent filler is polymethyl methacrylate for correcting nasolabial folds. PLLA and CaHA are synthetic fillers, laboratorymade substances that are not related to substances found in the native skin. 


\section{Collagen}

Collagen is a major component of human connective tissues, such as skin, cartilage, vasculature, and bone. The injectable forms of collagen can be purified from either bovine or human sources. These products are seldom used and were voluntary withdrawn from the U.S. market in 2010. They have since been supplanted by hyaluronic acids. ${ }^{58}$

\section{Hyaluronic Acid}

Currently, hyaluronic acids are the dominant facial filler agent. Hyaluronic acid is also a major component of connective tissues, especially in the human dermis. It hydrates, lubricates, and stabilizes connective tissues, and as skin ages, the amount of hyaluronic acid decreases in tissues. Hyaluronic acid contains no products of animal origin, and therefore eliminates the need for preinjection skin testing. ${ }^{63}$ The available hyaluronic acid products differ in their concentration, cross-linkage, and viscosity. Recent research focuses on the methods to produce more stable forms of hyaluronic acid that have longer in vivo retention times. ${ }^{64}$ The main patient concerns about dermal filler injections are pain and discomfort as well as postprocedural bruising and swelling. There is an increasing trend toward adding lidocaine solution to fillers and using microcannulas for injection techniques. ${ }^{58}$

\section{Poly-L-Lactic Acid}

PLLA is a deep tissue regenerator that provides soft tissue augmentation through stimulation of fibroblast production. It is a synthetic polymer that stimulates collagen synthesis through a foreign-body reaction. It was the first dermal filler developed to treat facial lipoatrophy in patients with human immunodeficiency virus. In general, PLLA is frequently and successfully used to treat hollowing of the cheek, nasolabial folds, prejowl folds, the malar area, and the temporal area. Studies have indicated that results last at least 3 years with additional treatment sessions, and patient satisfaction is high. ${ }^{65}$

\section{Calcium Hydroxylapatite}

CaHA is another synthetic, nonanimal, inorganic compound that is not immunogenic. In 2006, CaHA was approved by the FDA to treat lipoatrophy via subdermal implantation to correct moderate to severe facial wrinkles and folds. Corrective results last up to 12 to 20 months after injection. ${ }^{66}$

\section{Polymethyl Methacrylate}

The only FDA-approved permanent filler is polymethyl methacrylate. ${ }^{58}$ The main concerns of permanent fillers are the possibility of late-onset adverse events or displacement of the filler as facial structures change with age. Bellafill (Suneva Medical, Inc., Santa Barbara, California) is a third-generation filler that is composed of a suspension of polymethyl methacrylate beads in a bovine collagen delivery system with $0.3 \%$ lidocaine. The beads are not absorbed by the body but cause fibrotic granulation under the skin through foreign-body reactions. The beads are eventually encapsulated by endogenous collagen.

\section{Botulinum Toxin}

Botulinum toxin injection for treatment of facial wrinkles is the most frequently performed cosmetic procedure in the United States. ${ }^{67}$ The Clostridium botulinum bacterium produces eight serotypes of botulinum toxin protein $(A, B, C \alpha, C \beta$, $D, E, F$, and $G$ ). The most potent is the botulinum toxin serotype $A$, which is the one used for cosmetic treatments of glabellar lines and other hyperfunctional facial rhytides. ${ }^{68}$ Botulinum toxins inhibit the release of acetylcholine into the synaptic cleft and therefore result in temporary muscle paralysis. The clinical effects generally last $\sim 2$ to 6 months. ${ }^{69}$ There are three botulinum toxin A (BoNTA) serotypes approved by the FDA for cosmetic use: onabotulinumtoxinA (BOTOX Cosmetic, Allergan Pharmaceuticals, Westport, Ireland), abobotulinumtoxinA (Dysport, Ipsen Biopharm Ltd., Wrexham, United Kingdom), and incobotulinumtoxinA (Xeomin, Merz North America, Raleigh, North Carolina). ${ }^{70}$ There are five sources of botulinum toxin available worldwide. ${ }^{71}$ These various preparations of botulinum toxin are neither identical nor interchangeable as their reconstitution in various solutions, storage temperature, and properties after dilution differ. BOTOX is 4 times more potent on a per unit basis than Dysport, and both are used for cosmetic purposes. Xeomin is a highly purified formulation that is free from complexing proteins, reducing its immunogenic potential. ${ }^{72}$ In addition to treating already developed wrinkles, BoNTA has been shown to prevent the development of wrinkles. ${ }^{69}$

\section{Reconstructive Surgery}

Facial reconstructive surgery aims to correct anatomic defects and may include scar revision, craniomaxillofacial fracture repair, laceration repair, vascular malformation treatment, craniofacial and maxillofacial cleft operations, orthognathic surgery, and cancer reconstruction. Examples of cancer reconstruction include free flaps for head and neck cancer defects and local skin flaps for cutaneous tumors.

\section{Facial Fractures}

Facial fractures are often due to trauma and can be divided into three types of injuries: Le Fort fractures, zygomaticomaxillary complex (ZMC) fractures, and mandibular fractures.

Le Fort facial fractures of the midface are complex and classified into three categories. They all involve fracture of the pterygoid plates. Le Fort I fractures (horizontal) often result from a directed force on the maxillary alveolar rim in a downward direction. ${ }^{73}$ There is no orbital involvement in type I fractures. Le Fort II fractures (pyramidal) result from a blow to the lower or midmaxilla and are defined in part by separation of the maxilla from the cranial base at the zygomatic arch. Le Fort III fractures (transverse), also termed craniofacial disjunction, are often caused by an impact to the nasal bridge and are the most complex and devastating of the Le Fort fractures. These fractures are accompanied by severe intracranial trauma and result in complete separation of the facial skeleton from the skull base. 
ZMC fractures are the second most common facial fractures after nasal fractures and are also referred to as malar or cheekbone fractures. The most common causes of ZMC fractures include assault, falls, motor vehicle accidents, and sports injuries. The ZMC provides normal cheek contour and separates the orbital contents from the temporal fossa and maxillary sinus. ZMC fractures are classified into type A1 (zygomatic arch), type A2 (lateral orbital wall), type A3 (inferior orbital rim), type B (involving all four anatomical sites), and type $C$ (complex fractures with comminution of the zygomatic bone). ${ }^{74}$

Mandibular fractures are frequent injuries after facial trauma due to the mandible's angularity and relative lack of structural support. Mandibular fracture types can be classified by injury of the anatomic regions: condyle, coronoid process, ramus, angle, body, alveolus, parasymphysis, and symphysis.

\section{Management of Facial Fractures}

The ultimate goal in treating facial fractures is to obtain an accurate and stable reduction while minimizing external scars and deformity. For ZMC injuries that have fracture instability or comminution, an open reduction and internal fixation is indicated with the coronal approach as the main access for complex zygomatic arch repairs. This approach can lead to alopecia, loss of sensation posterior to the incision, risks of traction injury to the frontal branch of the facial nerve with temporal hollowing, and excessive blood loss. More recently, endoscopy has been used to assist in the treatment of ZMC and Le Fort III fractures. Endoscopy can be performed through stab incisions and thus avoids the need for extensive coronal exposure for zygomatic arch repairs. ${ }^{75}$ Endoscopy allows for in situ reduction and fixation under magnified visualization while only requiring small, well-concealed incisions.

Mandibular fractures were traditionally treated with closed reduction or open reduction with wire osteosynthesis. In addition, rigid internal fixation was developed and involved placement of interfragmentary titanium plates.

The main advances in facial reconstruction for these traumatic facial fractures are in new instruments and hardware. Individual anatomy is recreated on a computer using computed tomography data. Customized plates are designed, and the operative plan is simulated on a computer workstation. This technology allows surgeons to better plan the operation, showcase expectations to patients, and teach fellow surgeons. Patient-specific implants in various materials including titanium and silicone have now been developed and utilized. ${ }^{76}$ Additionally, resorbable plates and screws have been used in the treatment of mandibular fractures. ${ }^{77-79}$ These plates are of particular use in children, whose facial bones continue to grow. Rigid fixation techniques now more commonly utilize smaller fixation plates instead of larger plates. ${ }^{80,81}$

\section{Facial Reanimation}

Facial paralysis can be a consequence of traumatic facial nerve injury, iatrogenic injury, oncologic resection, temporal bone surgery, skull-base surgery, congenital syndromes, and viral infections. ${ }^{82}$ Facial reanimation surgery involves using surgi- cal techniques to improve the facial deformity caused by facial paralysis with the goal of improving facial symmetry or restoring mimetic function. There are five types of repair: (1) neural techniques; (2) musculofascial transposition techniques; (3) microneurovascular transfer; (4) facial plastic surgery procedures; and (5) use of prosthetics. ${ }^{82,83}$ Dynamic procedures aim to restore voluntary movement. These include cranial nerve XII-to-cranial nerve VII nerve transfers, interpositional grafts, cross-facial nerve grafts, dynamic musculofascial transpositions, and free flaps with cross-facial nerve grafting for reconstruction. Static procedures to treat facial paralysis include the use of upper eyelid alloplast implants, fascia lata slings, facelifts, browlifts, and eyelid procedures. ${ }^{82}$ These techniques can provide marked cosmetic improvement and can restore function, particularly in eye protection, mastication, and speech.

\section{Microtia}

Microtia is a congenital malformation of the external ear, which results in a disorganized remnant of cartilage in the auricle. Reconstruction may be performed through a multistage process consisting of the implantation of a rigid framework and the subsequent creation of the ear lobe and crease behind the ear. Reconstruction of the external ear can be performed with prosthetic ear replacement, prosthetic frameworks, and autologous cartilage. Historically, microtia repair was a four-stage operation with (1) procurement of cartilage of the chest wall; (2) construction and placement of cartilage framework; (3) lobule rotation, conchal excavation, and tragus formation; and (4) elevation of the pinna. ${ }^{84}$ With recent advances and refinements in framework carving and techniques, it is a two-stage reconstruction process today: (1) creation of a 3-D costal cartilage framework and (2) ear elevation operation. ${ }^{85}$ One study that compared the use of rib cartilage versus porous polyethylene implant for microtia reconstruction showed neither material to be superior; however, the polyethylene implants achieved a better cosmetic outcome in terms of ear definition, shape, and size. ${ }^{86}$ The downside was that polyethylene implants had a higher risk for infection and extrusion. ${ }^{86}$ Research in tissue engineering is currently being performed, and newer alloplasts are being used with aspirations that the use of engineered tissues and alloplasts may one day replace autologous cartilage.

\section{Otoplasty}

Otoplasty is the surgical procedure to treat congenitally prominent ears. Otoplasty can be either cartilage splitting or cartilage sparing. Cartilage-splitting techniques involve incisions through the cartilage and repositioning of large blocks of auricular cartilage. Cartilage-sparing techniques avoid full-thickness incisions but create angles and curls in the cartilage for contouring. Most surgeons now perform cartilage-sparing otoplasty. ${ }^{87,88}$

\section{Future Direction of Facial Plastic Surgery}

Current trends in facial plastic surgery include increased utilization of nonsurgical techniques such as fillers and 
neurotoxins to treat the aging face, development of new laser technologies, utilization of 3-D imaging techniques for individualized plating in maxillofacial surgery in trauma, and minimally invasive techniques such as endoscopic approaches to minimize scaring.

\section{Combination of Fillers and вотоX}

BoNTA has now been a popular agent for cosmetic procedures for over 20 years. Its injection has proved to be safe, with a high degree of satisfaction. BoNTA research studies its effects and safety for expanding its indications for medical treatments. ${ }^{89}$

In addition, there is research in development of various combination therapies with BoNTA and other modalities including fillers, intense pulsed light, laser modalities, and dermabrasion. ${ }^{90-93}$ Aging is a complicated multifactorial process that causes undesirable wrinkles, furrows, sagging, dyspigmentation, and changes in skin textures. Two major causes of the aging processes are volume loss and muscular hyperactivity. There is current research and development in combination treatments with dermal fillers and BoNTA to simultaneously restore volume and relax muscle pull to more effectively recontour the face. ${ }^{94}$ Combining BoNTA with intradermal fillers such as hyaluronan not only gives an immediate resting result but also allows the effects of the filler to last twice as long. ${ }^{95,96}$

Moreover, Revance Therapeutics, Inc. (Newark, California) is developing a new BoNTA product called RT002, a novel injectable formulation of BoNTA that consists of a purified neurotoxin and a patented TransMTS peptide. ${ }^{97}$ This product is designed to remain in the targeted treatment area and limit the spread of BoNTA to adjacent muscles. This new peptide is hypothesized to allow higher targeted doses of BoNTA. Based on the preclinical data, the RT002 durability is up to 7 months, compared with the average 2 to 6 months of current BoNTA sources. ${ }^{97}$

Injection techniques and patterns in BoNTA applications are also evolving. ${ }^{98}$ An increasing number of procedures are performed on the middle and lower face rather than just on the upper face. ${ }^{96}$ The combination of BoNTA and hyaluronic acid filler is now the standard approach for the lower face. Another minimally invasive facial rejuvenation technique has been the use of BoNTA with augmentation and facial sculpting using autologous adipose tissue, which has been shown to extend results. ${ }^{96}$ Blunt cannulas are now used by many providers to distribute fillers after an initial puncture is made through the skin allowing injection in multiple vectors with reduced needle trauma.

\section{Three-Dimensional Imaging}

One of the most exciting trends in facial plastic surgery is the development of computer-guided 3-D reconstruction techniques. For example, computer-guided orbital reconstruction with mirror image overlay navigation improved outcomes in complex orbital reconstructions. ${ }^{99}$ In addition, surgical navigation technology has been shown to be a new effective auxiliary method for improving the treatment results for zygomatic fracture.

\section{Three-Dimensional Printing}

3-D printing technology is an expanding and innovative field in medicine and surgery. ${ }^{100} 3$-D printing-based tactile prototype models are helpful in skull reconstruction, correction of craniosynostosis, simulating Le Fort osteotomies, and creation of ideal orbital wall meshes for orbital wall repairs. Facial reconstruction is a complicated procedure that often requires significant intraoperative time in contouring the titanium plates used to link adjacent bone together while the patient is under anesthesia. By creating a 3-D replica of the individual patient's bony anatomy, these titanium plates can be contoured before surgery and reduce operation time. ${ }^{101,102}$ In addition, this method allows the creation of a precise fit, resulting in an improved aesthetic form, and reduces the risk for corrective surgery. ${ }^{102}$ Bedside 3-D printing is another emerging technology and can create 3-D prostheses and models for individualized patient education, allowing preoperative surgical planning, creating patient-specific intraoperative guidance tools, and fashioning patient-specific implants. $^{103}$

\section{Endoscopy}

As mentioned previously, there is a popular trend in facial plastic surgery toward minimally invasive techniques. Endoscopy has been shown to be safe and effective in the management of orbital floor fractures and zygomatic fractures. ${ }^{104,105}$ Endoscopy allows good visualization of the anatomy without the need for extensive access incisions. ${ }^{106}$ It minimizes scalp scar, decreases forehead numbness, shortens hospital stay, and provides a faster, more comfortable postoperative recovery for the patient. ${ }^{105}$

\section{Advances in Biomaterials and Bioengineered Interfaces}

The use of rigid implants is crucial for adequate bone immobilization in skeletal facial reconstruction. Historically, there have been postoperative complications of hardware use including pain from plates, loosening of screws, palpability of metal plates, temperature sensitization due to implants, increased maxillary and frontal sinus infections, radiographic artifacts, and hypersensitivity reaction to various alloys. ${ }^{78}$ The use of nonmetallic materials would reduce these postoperative concerns, and research in this area is promising. Resorbable fixation material has been well studied in pediatric craniofacial surgery with good results. ${ }^{79,107}$ Eppley studied the use of plates and screws composed of a specific poly Llactic acid-polyglycolic acid material, concluding it can be effectively and safely used in the midface. ${ }^{78}$

\section{Tissue Engineering}

Repair of craniofacial injuries due to trauma, tumor removal, or congenital abnormalities is a large aspect of facial plastic surgery, and there is a need for both functional and aesthetic restoration of a complex variety. ${ }^{108}$ Autologous grafts such as those harvested from the cranium, fibula, or iliac crest are the gold standard for head and neck reconstructions. However, autologous graft harvests are limited in availability, cause donor site morbidity, lack precision in contouring of donor graft shape, and have an inherent difference in the structure 
and biomechanics of the donor site and graft site. Engineering of personalized human bone grafts is an exciting field of facial plastic surgery. The key strategies involve the use of bioactive scaffolds, cell-seeded scaffolds, and autologous bone grafts grown in vitro. ${ }^{108}$ Bioactive acellular scaffolds utilize biodegradable synthetic materials with osteoinductive factors that induce the recruitment of host cells into the scaffold and guide host cell-bone ingrowth. ${ }^{108}$ Cell-seeded scaffolds combine exogenous cells usually harvested from bone marrow with bioactive molecules in scaffolds. These types of scaffolds seeded with bone marrow cells and platelet-rich plasma were shown to enhance osteogenesis. ${ }^{109,110}$ One famous example of successful tissue engineering is the Vacanti total external ear reconstruction with a polyglycolic acid polylactic acid construct with seeded chondrocytes. ${ }^{111}$

\section{Advances in Facial Reanimation}

Current management of facial reanimation uses static biomaterial implants such as polymer or allograft tissue matrices to support de-enervated sagging tissue or microsurgical transfers of muscle to give movement to the paralyzed side. There is research into regenerative implants that could be composed of autologous myocytes cultured on matrix scaffolding that can respond to neural input for control. ${ }^{112}$ There is also research in tissue-engineered constructs that have the potential to regenerate cells in various scaffolds as well as development of novel neuromuscular interfaces and replacement tissues for restoring facial function to create a more natural result in facial reanimation surgery. ${ }^{113}$ Further studies are exploring neuroelectrical prosthetic devices to drive paralyzed musculature based on cues from the healthy side. For example, Ledgerwood et al developed an electroactive polymer artificial muscle device that could potentially restore lost muscular contraction for use as an eyeblink prosthesis. ${ }^{114}$

In terms of advancements in surgical techniques, there are procedures being developed to drive the native facial muscles with the masseteric branch of the trigeminal nerve with minimal injuries to the donor site, as well as studies on using a cross-facial nerve grafts for the reanimation of the paralyzed face. ${ }^{115-118}$ Cross-facial nerve grafts utilize the contralateral healthy facial nerve to reinnervate the paralyzed muscles. ${ }^{119,120}$

There is also extensive basic science research in improving the management of facial reanimation that focuses on improving axonal transversement of nerve grafts, decreasing detrimental neural oversprouting and hyperstimulation, and improving the target accuracy of the regenerated nerve. ${ }^{121}$ The "facegram" is a new tool that is being developed to acquire 3-D videographs of patients performing a set of facial expressions and converting the data into graphical information for analysis. Along this line of research is the development of a central database warehouse to allow physicians to upload individual patient facegram data. In the future, the central data set could help physicians better determine the optimal approaches for individual patients because it would offer a reference of available approaches and postoperative results that would augment individual practice experiences. ${ }^{121}$

\section{Facial Reconstruction and Transplantation}

Severe trauma to the face after burns or bullet trauma can be disfiguring and difficult to treat because the face is a complex entity in its form and function. ${ }^{122}$ Over time, there have been advancements from using local soft tissue flaps and rigid fixation in reconstruction to the invention of microsurgical free tissue transfer, which allows clinicians to repair complex facial defects using free flaps and replace significant amounts of missing tissue. ${ }^{122}$ The advantage of free flaps is that they can be modified extensively for better reconstructions. Most of the face and neck are composed of fasciocutaneous structure and can be more easily repaired via microsurgical procedures; however, injuries involving neuromusculature of the midface may warrant a facial transplantation. ${ }^{122}$

The midface is a critical component of the face; it is the central region where facial movement is initiated. This central neuromuscular component preserves the individual's identity, and movement in this area must be natural postreconstruction. ${ }^{122}$ Facial transplantations are more technically challenging than free flap transfers. The essential concept in facial transplantation is that of angioneurosome, which is the idea that the design of the flap should be based on blood supply, neuromuscular unit, and muscular origin and insertion, as well as preservation of rigid facial structures and cutaneous ligaments. ${ }^{122}$ Facial transplantation allows transferring of various skin, soft tissue, and bone that can replace the lost tissue of the patient with an exact anatomic and functional match, but there are risks associated with immunosuppressant use, which increase the risk for infections, malignancies, and end-organ toxicities. ${ }^{122}$

The first near-total face transplantation in the United States was performed at the Cleveland Clinic in 2008. Since then, several partial and total face transplantations have been performed in the United States. After a face transplantation, the patient may look similar to the donor but because of variations in skeletal structure and facial shape of the recipient, the result is a hybrid of the two faces. ${ }^{122}$

\section{Stem Cells}

Regenerative medicine plays an important role in many aspects of medicine and surgery. In the field of facial plastic surgery, stem cells are often used for bony and soft tissue defects, nonhealing wounds, and skin rejuvenation. ${ }^{123}$ One example is adipose tissue-derived stem cells that secrete angiogenic growth factors like vascular endothelial growth factor, which have been shown to aid in marked improvements in survival rate of transplanted fat grafts. ${ }^{124}$ Stem cells have also been shown to accelerate wound healing, reduce scar appearance, and prevent allotransplant rejection. ${ }^{125}$ Adipose tissue-derived stem cells can be isolated from lipoaspirate blood and saline fraction in as short as $30 \mathrm{mi}-$ nutes. ${ }^{126}$ Unfortunately, its quick availability and popularity have led to increased marketing of false "stem cell therapies" and scams. $^{127}$

\section{Wound Healing}

Last but not least, wound healing is an important aspect of facial plastic surgery. It is crucial to maintain the basic 
principles of wound care, especially in the face. The principles include minimizing infection, maximizing tissue oxygenation, ensuring adequate nutrition, and determining adequate debridement when indicated. However, over the last decade, there have been advancements in adjunctive products to aid in wound healing. Multiple biological, synthetic, and genetically derived factors; bioengineered tissue substitutes; vacuum-assisted closure devices; and hyperbaric oxygen therapies allow clinicians to proactively treat facial wounds and reduce wound-healing complications, such as infection and scar formation. ${ }^{128}$

Growth factors are one adjunctive product to enhance healing of wounds. Examples of growth factors include recombinant human platelet-derived growth factor, anti-deltalike ligand 4, and recombinant human transforming growth factor $\beta-3 .{ }^{129}$ Recombinant human platelet-derived growth factor has been used by otolaryngologists to improve wound healing in patients who have undergone irradiation. The irradiation of wounds may alter growth factor presence and create higher levels of growth factor inhibitor. ${ }^{128}$ Anti-deltalike ligand 4 is a growth factor that increases tissue vascularity and thereby increases the rate of wound healing. ${ }^{130}$ Intradermal injection of recombinant human transforming growth factor $\beta-3$ has been shown to reduce scarring. ${ }^{128}$

Biologic products such as platelet-rich plasma, plateletrich fibrin matrix, and autologous platelet-rich gel are also used to enhance healing. Platelet-rich plasma reduced infection in acute wounds and enhanced wound healing in chronic wounds. ${ }^{131}$ Some studies suggested that platelet-rich fibrin matrix injection of the dermis may activate fibroblasts, induce collagen deposition, and increase angiogenesis of the wound. ${ }^{132}$ Autologous platelet-rich gel has also been shown to significantly increase wound closure rate. ${ }^{128}$

Other adjunctive techniques to enhance wound healing that are still in early research phases include vacuum-assisted closure, bioengineered skin, shock-wave therapy, pulsed radiofrequency wound healing, hyperbaric oxygen, and fetal wound healing. Of these, vacuum devices and hyperbaric oxygen therapy are the most studied. Vacuum devices improve blood flow by increasing the pressure gradient between the interstitial space and newly forming capillaries. It also removes excess fluid, reduces edema, decreases bacterial load, and increases granulation in the tissue bed. ${ }^{128}$ Hyperbaric oxygen stimulates angiogenesis and fibroblast proliferation by causing vasoconstriction and increased partial pressures of oxygen in the blood. ${ }^{128}$

As for bioengineered skin for facial plastic surgery, research in this field is limited. Currently there is one product called Apligraf (Organogenesis, Inc., Canton, Massachusetts) available as a permanent composite of dermoepidermal graft that is cultured from neonatal forehead skin, which has shown potential in enhancing wound healing. ${ }^{128}$ Shockwave therapy has been shown to induce expression of several genes and increase the production of growth factors that promote wound healing. ${ }^{133}$ Studies in mice showed that pulsed radiofrequency treatment increases wound contracture and tissue granulation. ${ }^{134}$ Perhaps the most novel concept in wound healing is that of fetal wound healing. In fetal wounds, there is more type III collagen instead of type I, hyaluronic acid is expressed in higher amounts, modulators of collagen creation are upregulated, and inflammatory mediators are decreased in fetal tissue. ${ }^{135,136}$ Due to these differences, fetal skin repairs itself quickly and without scarring. Although scarless healing is still far in the future, the application of these concepts in fetal wound healing to adult wound healing may one day produce scarless healing in adults. $^{128}$

\section{Conclusion}

Facial plastic surgery is a broad field of otolaryngology surgery that involves reconstructive and cosmetic surgery techniques in addition to biomaterials, lasers, and other adjunct materials to improve surgical outcomes. We hope that this article has provided a good overview of facial plastic surgery and previewed the upcoming advances in the field of facial plastic surgery. There are exciting research studies in the fields of dermal fillers, 3-D imaging and printing, endoscopy, new biomaterials and tissue engineering, new surgical techniques in facial reanimation and facial transplantation, stem cell research, and enhancements in wound healing. In conclusion, facial plastic surgery is an important field of surgery that can make lifesaving and life-changing transformations in patients' individual lives and in society. It is an ever-evolving field that leads innovation in surgical techniques, technological and computer-based advancements, biomaterials research, and minimally invasive nonsurgical and surgical procedures for facial rejuvenation and reconstruction.

\section{References}

1 Bhattacharya S. Jacques Joseph: father of modern aesthetic surgery. Indian J Plast Surg 2008;41(Suppl):S3-S8

2 Behrbohm H, Briedigkeit W, Kaschke O. Jacques Joseph: father of modern facial plastic surgery. Arch Facial Plast Surg 2008;10(5): 300-303

3 Gillies HD. Plastic Surgery of the Face Based on Selected Cases of War Injuries of the Face Including Burns, with Original Illustrations. London, UK: Frowde; 1920. Available at: https://archive. org/details/plasticsurgeryofo0gilluoft. Accessed August 31, 2015

4 Triana RJ Jr. Sir Harold Gillies. Arch Facial Plast Surg 1999;1(2): 142-143

5 Spencer CR. Sir Harold Delf Gillies, the otolaryngologist and father of modern facial plastic surgery: review of his rhinoplasty case notes. J Laryngol Otol 2015;129(6):520-528

6 AAFPRS. Mission Statement. American Academy of Facial Plastic and Reconstructive Surgery (2015). Available at: http://www. aafprs.org/patient/about_us/pa_mission.html. Accessed August 31, 2015

7 Larrabee WF Jr. The International Federation of Facial Plastic Surgery Societies. JAMA Facial Plast Surg 2013;15(6):403-404

8 Neaman KC, Boettcher AK, Do VH, et al. Cosmetic rhinoplasty: revision rates revisited. Aesthet Surg J 2013;33(1):31-37

9 Ors S, Ozkose M, Ors S. Comparison of various rhinoplasty techniques and long-term results. Aesthetic Plast Surg 2015; 39(4):465-473

10 Gunter JP, Landecker A, Cochran CS. Frequently used grafts in rhinoplasty: nomenclature and analysis. Plast Reconstr Surg 2006;118(1):14e-29e 
11 Parker Porter J. Grafts in rhinoplasty: alloplastic vs. autogenous. Arch Otolaryngol Head Neck Surg 2000;126(4):558-561

12 James SE, Kelly MH. Cartilage recycling in rhinoplasty: polydioxanone foil as an absorbable biomechanical scaffold. Plast Reconstr Surg 2008;122(1):254-260

13 Greywoode JD, Pribitkin EA. Sonic rhinoplasty: histologic correlates and technical refinements using the ultrasonic bone aspirator. Arch Facial Plast Surg 2011;13(5):316-321

14 Lopez MA, Westine JG, Toriumi DM. The role of powered instrumentation in rhinoplasty and septoplasty. J Long Term Eff Med Implants 2005;15(3):283-288

15 Toriumi DM, Dixon TK. Assessment of rhinoplasty techniques by overlay of before-and-after 3D images. Facial Plast Surg Clin North Am 2011;19(4):711-723, ix

16 Cheng ET, Perkins SW. Rhytidectomy analysis: twenty years of experience. Facial Plast Surg Clin North Am 2003;11(3):359-375

17 Miller TR, Eisbach KJ. SMAS facelift techniques to minimize stigmata of surgery. Facial Plast Surg Clin North Am 2005; 13(3):421-431

18 van der Lei B, Cromheecke M, Hofer SOP. The purse-string reinforced SMASectomy short scar facelift. Aesthet Surg J 2009; 29(3):180-188

19 Atiyeh BS, Dibo SA, Costagliola M, Hayek SN. Barbed sutures "lunch time" lifting: evidence-based efficacy. J Cosmet Dermatol 2010;9(2):132-141

20 Benedetto AV. The lunchtime face lift. Skinmed 2006;5(3): 146-147

21 Sulamanidze MA, Paikidze TG, Sulamanidze GM, Neigel JM. Facial lifting with "APTOS" threads: featherlift. Otolaryngol Clin North Am 2005;38(5):1109-1117

22 Rodriguez-Bruno K, Papel ID. Rhytidectomy: principles and practice emphasizing safety. Facial Plast Surg 2011;27(1):98-111

23 Castañares S. Facial nerve paralyses coincident with, or subsequent to, rhytidectomy. Plast Reconstr Surg 1974;54(6):637-643

24 Prendiville S, Weiser S. Management of anesthesia and facility in facelift surgery. Facial Plast Surg Clin North Am 2009;17(4): 531-538, v

25 American Society for Aesthetic Plastic Surgery. Cosmetic Surgery National Data Bank: 2006 statistics. Available at: http://www. surgery.org/sites/default/files/2014-Stats.pdf. Accessed August 20, 2015

26 Lam SM, Glasgold MJ, Glasgold RA. Contemporary fat grafting. In: Shiffman MA, Mirrafati SJ, Lam SM, Cueteaux CG, eds. Simplified Facial Rejuvenation. Berlin, Heidelberg, Germany: Springer; 2008:217-224

27 Naik MN, Honavar SG, Das S, Desai S, Dhepe N. Blepharoplasty: an overview. J Cutan Aesthet Surg 2009;2(1):6-11

28 Korchia D, Braccini F, Paris J, Thomassin J. Transconjunctival approach in lower eyelid blepharoplasty. Can J Plast Surg 2003; 11(3): $166-170$

29 de la Torre JI, Martin SA, De Cordier BC, Al-Hakeem MS, Collawn SS, Vásconez LO. Aesthetic eyelid ptosis correction: a review of technique and cases. Plast Reconstr Surg 2003;112(2):655-660, discussion 661-662

30 Martin JJ Jr. Upper eyelid blepharoplasty with ptosis repair by levator aponeurectomy. JAMA Facial Plast Surg 2015;17(3): 224-225

31 Connell BF, Lambros VS, Neurohr GH. The forehead lift: techniques to avoid complications and produce optimal results. Aesthetic Plast Surg 1989;13(4):217-237

32 Yalçınkaya E, Cingi C, Söken H, Ulusoy S, Muluk NB. Aesthetic analysis of the ideal eyebrow shape and position. Eur Arch Otorhinolaryngol 2016;273(2):305-310

33 Dayan SH, Perkins SW, Vartanian AJ, Wiesman IM. The forehead lift: endoscopic versus coronal approaches. Aesthetic Plast Surg 2001;25(1):35-39
34 Tower RN, Dailey RA. Endoscopic pretrichial brow lift: surgical indications, technique and outcomes. Ophthal Plast Reconstr Surg 2004;20(4):268-273

35 Bunagan MJK, Banka N, Shapiro J. Hair transplantation update: procedural techniques, innovations, and applications. Dermatol Clin 2013;31(1):141-153

36 Dua A, Dua K. Follicular unit extraction hair transplant. J Cutan Aesthet Surg 2010;3(2):76-81

37 Headington JT. Transverse microscopic anatomy of the human scalp. A basis for a morphometric approach to disorders of the hair follicle. Arch Dermatol 1984;120(4):449-456

38 Rose PT, Nusbaum B. Robotic hair restoration. Dermatol Clin 2014;32(1):97-107

39 Avram MR, Watkins SA. Robotic follicular unit extraction in hair transplantation. Dermatol Surg 2014;40(12):1319-1327

40 Harris JA. Follicular unit extraction. Facial Plast Surg Clin North Am 2013;21(3):375-384

41 Zakopoulou N, Kontochristopoulos G. Superficial chemical peels. J Cosmet Dermatol 2006;5(3):246-253

42 Fulton JE, Porumb S. Chemical peels: their place within the range of resurfacing techniques. Am J Clin Dermatol 2004;5(3): 179-187

43 Clark E, Scerri L. Superficial and medium-depth chemical peels. Clin Dermatol 2008;26(2):209-218

44 Fischer TC, Perosino E, Poli F, Viera MS, Dreno B; Cosmetic Dermatology European Expert Group. Chemical peels in aesthetic dermatology: an update 2009. J Eur Acad Dermatol Venereol 2010;24(3):281-292

45 Fulton JE Jr. Dermabrasion, chemabrasion, and laserabrasion. Historical perspectives, modern dermabrasion techniques, and future trends. Dermatol Surg 1996;22(7):619-628

46 Alster TS. Cutaneous resurfacing with $\mathrm{CO} 2$ and erbium: YAG lasers: preoperative, intraoperative, and postoperative considerations. Plast Reconstr Surg 1999;103(2):619-632, discussion 633-634

47 Goldberg DJ. Lasers for facial rejuvenation. Am J Clin Dermatol 2003;4(4):225-234

48 Trelles MA, Mordon S, Benítez V, Levy JL. Er:YAG laser resurfacing using combined ablation and coagulation modes. Dermatol Surg 2001;27(8):727-734

49 Lipozenčić J, Mokos ZB. Will nonablative rejuvenation replace ablative lasers? Facts and controversies. Clin Dermatol 2013; 31(6):718-724

50 Goldberg DJ. Non-ablative subsurface remodeling: clinical and histologic evaluation of a 1320-nm Nd:YAG laser. J Cutan Laser Ther 1999;1(3):153-157

51 Bitter PH. Noninvasive rejuvenation of photodamaged skin using serial, full-face intense pulsed light treatments. Dermatol Surg 2000;26(9):835-842, discussion 843

52 Jih MH, Kimyai-Asadi A. Fractional photothermolysis: a review and update. Semin Cutan Med Surg 2008;27(1):63-71

53 Bodendorf MO, Grunewald S, Wetzig T, Simon JC, Paasch U. Fractional laser skin therapy. J Dtsch Dermatol Ges 2009;7(4): 301-308

54 Paasch U, Haedersdal M. Laser systems for ablative fractional resurfacing. Expert Rev Med Devices 2011;8(1):67-83

55 Loesch MM, Somani A-K, Kingsley MM, Travers JB, Spandau DF. Skin resurfacing procedures: new and emerging options. Clin Cosmet Investig Dermatol 2014;7:231-241

56 Donath AS, Glasgold RA, Glasgold MJ. Volume loss versus gravity: new concepts in facial aging. Curr Opin Otolaryngol Head Neck Surg 2007;15(4):238-243

57 de Maio M. The minimal approach: an innovation in facial cosmetic procedures. Aesthetic Plast Surg 2004;28(5):295-300

58 Ballin AC, Brandt FS, Cazzaniga A. Dermal fillers: an update. Am J Clin Dermatol 2015;16(4):271-283 
59 Jung D-W, Kim YH, Kim TG, et al. Improvement of fat transplantation: fat graft with adipose-derived stem cells and oxygengenerating microspheres. Ann Plast Surg 2015;75(4):463-470

60 Locke MB, de Chalain TMB. Current practice in autologous fat transplantation: suggested clinical guidelines based on a review of recent literature. Ann Plast Surg 2008;60(1):98-102

61 Goldfarb RM, Shapiro AL. Benefits of autologous fat grafting using fat mixed with platelet-rich fibrin matrix (PRFM) selphyl. Am J Cosmet Surg 2012;29(1):62-64

62 Yuksel E, Choo J, Wettergreen M, Liebschner M. Challenges in soft tissue engineering. Semin Plast Surg 2005;19(3):261-270

63 Saylan Z. Facial fillers and their complications. Aesthet Surg J 2003;23(3):221-224

64 Eppley BL, Dadvand B. Injectable soft-tissue fillers: clinical overview. Plast Reconstr Surg 2006;118(4):98e-106e

65 Levy RM, Redbord KP, Hanke CW. Treatment of HIV lipoatrophy and lipoatrophy of aging with poly-L-lactic acid: a prospective 3year follow-up study. J Am Acad Dermatol 2008;59(6):923-933

66 Bass LS, Smith S, Busso M, McClaren M. Calcium hydroxylapatite (Radiesse) for treatment of nasolabial folds: long-term safety and efficacy results. Aesthet Surg J 2010;30(2):235-238

67 Carruthers J, Fagien S, Matarasso SL; Botox Consensus Group. Consensus recommendations on the use of botulinum toxin type $\mathrm{a}$ in facial aesthetics. Plast Reconstr Surg 2004;114(6, Suppl):1S-22S

68 Carruthers JA, Lowe NJ, Menter MA, et al; BOTOX Glabellar Lines I Study Group. A multicenter, double-blind, randomized, placebocontrolled study of the efficacy and safety of botulinum toxin type $\mathrm{A}$ in the treatment of glabellar lines. J Am Acad Dermatol 2002;46(6):840-849

69 Binder WJ. Long-term effects of botulinum toxin type A (Botox) on facial lines: a comparison in identical twins. Arch Facial Plast Surg 2006;8(6):426-431

70 Small R. Botulinum toxin injection for facial wrinkles. Am Fam Physician 2014;90(3):168-175

71 Trindade De Almeida AR, Secco LC, Carruthers A. Handling botulinum toxins: an updated literature review. Dermatol Surg 2011;37(11):1553-1565

72 Dessy LA, Fallico N, Mazzocchi M, Scuderi N. Botulinum toxin for glabellar lines: a review of the efficacy and safety of currently available products. Am J Clin Dermatol 2011;12(6):377-388

73 Rogers GM, Allen RC. Le Fort fractures. In: Black EH, Nesi FA, Calvano CJ, Gladstone GJ, Levine MR, eds. Smith and Nesi's Ophthalmic Plastic and Reconstructive Surgery. New York, NY: Springer; 2012:283-295

74 Zingg M, Laedrach K, Chen J, et al. Classification and treatment of zygomatic fractures: a review of 1,025 cases. J Oral Maxillofac Surg 1992;50(8):778-790

75 Strong EB, Kim KK, Diaz RC. Endoscopic approach to orbital blowout fracture repair. Otolaryngol Head Neck Surg 2004; 131(5):683-695

76 Dérand P, Rännar L-E, Hirsch J-M. Imaging, virtual planning, design, and production of patient-specific implants and clinical validation in craniomaxillofacial surgery. Craniomaxillofac Trauma Reconstr 2012;5(3):137-144

77 Suzuki T, Kawamura H, Kasahara T, Nagasaka H. Resorbable polyL-lactide plates and screws for the treatment of mandibular condylar process fractures: a clinical and radiologic follow-up study. J Oral Maxillofac Surg 2004;62(8):919-924

78 Eppley BL. Zygomaticomaxillary fracture repair with resorbable plates and screws. J Craniofac Surg 2000;11(4):377-385

79 Eppley BL, Sadove AM, Havlik RJ. Resorbable plate fixation in pediatric craniofacial surgery. Plast Reconstr Surg 1997;100(1): 1-7, discussion 8-13

80 Hammer B, Schier P, Prein J. Osteosynthesis of condylar neck fractures: a review of 30 patients. Br J Oral Maxillofac Surg 1997; 35(4):288-291
81 Cabrini Gabrielli MA, Real Gabrielli MF, Marcantonio E, HochuliVieira E. Fixation of mandibular fractures with $2.0-\mathrm{mm}$ miniplates: review of 191 cases. J Oral Maxillofac Surg 2003;61(4): 430-436

82 Tate JR, Tollefson TT. Advances in facial reanimation. Curr Opin Otolaryngol Head Neck Surg 2006;14(4):242-248

83 Garcia RM, Hadlock TA, Klebuc MJ, Simpson RL, Zenn MR, Marcus JR. Contemporary solutions for the treatment of facial nerve paralysis. Plast Reconstr Surg 2015;135(6):1025e-1046e

84 Tanzer RC. Microtia-a long-term follow-up of 44 reconstructed auricles. Plast Reconstr Surg 1978;61(2):161-166

85 Nagata S. A new method of total reconstruction of the auricle for microtia. Plast Reconstr Surg 1993;92(2):187-201

86 Constantine KK, Gilmore J, Lee K, Leach J Jr. Comparison of microtia reconstruction outcomes using rib cartilage vs porous polyethylene implant. JAMA Facial Plast Surg 2014;16(4):240-244

87 Kelley P, Hollier L, Stal S. Otoplasty: evaluation, technique, and review. J Craniofac Surg 2003;14(5):643-653

88 Stal S, Klebuc K. Advances in otoplasty: principles and techniques. Key Issues Plast Cosmet Surg 2001;17:143-160

89 Freeman SR, Cohen JL. New neurotoxins on the horizon. Aesthet Surg J 2008;28(3):325-330

90 West TB, Alster TS. Effect of botulinum toxin type A on movement-associated rhytides following $\mathrm{CO} 2$ laser resurfacing. Dermatol Surg 1999;25(4):259-261

91 Zimbler MS, Holds JB, Kokoska MS, et al. Effect of botulinum toxin pretreatment on laser resurfacing results: a prospective, randomized, blinded trial. Arch Facial Plast Surg 2001;3(3):165-169

92 Yamauchi PS, Lask G, Lowe NJ. Botulinum toxin type A gives adjunctive benefit to periorbital laser resurfacing. J Cosmet Laser Ther 2004;6(3):145-148

93 Carruthers J, Carruthers A. The effect of full-face broadband light treatments alone and in combination with bilateral crow's feet Botulinum toxin type A chemodenervation. Dermatol Surg 2004; 30(3):355-366, discussion 366

94 Coleman KR, Carruthers J. Combination therapy with BOTOX and fillers: the new rejuvnation paradigm. Dermatol Ther 2006; 19(3):177-188

95 Carruthers J, Carruthers A. A prospective, randomized, parallel group study analyzing the effect of BTX-A (Botox) and nonanimal sourced hyaluronic acid (NASHA, Restylane) in combination compared with NASHA (Restylane) alone in severe glabellar rhytides in adult female subjects: treatment of severe glabellar rhytides with a hyaluronic acid derivative compared with the derivative and BTX-A. Dermatol Surg 2003;29(8):802-809

96 Carruthers JDA, Glogau RG, Blitzer A; Facial Aesthetics Consensus Group Faculty. Advances in facial rejuvenation: botulinum toxin type a, hyaluronic acid dermal fillers, and combination therapies -consensus recommendations. Plast Reconstr Surg 2008;121(5, Suppl):5S-30S, quiz 31S-36S

97 Garcia-Murray E, Velasco Villasenor ML, Acevedo B, et al. Safety and efficacy of RT002, an injectable botulinum toxin type A, for treating glabellar lines: results of a phase $1 / 2$, open-label, sequential dose-escalation study. Dermatol Surg 2015;41(Suppl 1): S47-S55

98 Flynn TC. Advances in the use of botulinum neurotoxins in facial esthetics. J Cosmet Dermatol 2012;11(1):42-50

99 Bly RA, Chang S-H, Cudejkova M, Liu JJ, Moe KS. Computer-guided orbital reconstruction to improve outcomes. JAMA Facial Plast Surg 2013;15(2):113-120

100 Choi JW, Kim N. Clinical application of three-dimensional printing technology in craniofacial plastic surgery. Arch Plast Surg 2015;42(3):267-277

101 Azuma M, Yanagawa T, Ishibashi-Kanno N, et al. Mandibular reconstruction using plates prebent to fit rapid prototyping 3dimensional printing models ameliorates contour deformity. Head Face Med 2014;10:45 
102 Marro A, Bandukwala T, Mak W. Three-dimensional printing and medical imaging: a review of the methods and applications. Curr Probl Diagn Radiol 2016;45(1):2-9

103 Chae MP, Rozen WM, McMenamin PG, Findlay MW, Spychal RT, Hunter-Smith DJ. Emerging applications of bedside 3D printing in plastic surgery. Front Surg 2015;2:25

104 Cheung K, Voineskos SH, Avram R, Sommer DD. A systematic review of the endoscopic management of orbital floor fractures. JAMA Facial Plast Surg 2013;15(2):126-130

105 Chen CT, Lai JP, Chen YR, Tung TC, Chen ZC, Rohrich RJ. Application of endoscope in zygomatic fracture repair. Br J Plast Surg 2000; 53(2):100-105

106 Czerwinski M, Lee C. The rationale and technique of endoscopic approach to the zygomatic arch in facial trauma. Facial Plast Surg Clin North Am 2006;14(1):37-43

107 Goodrich JT, Sandler AL, Tepper O. A review of reconstructive materials for use in craniofacial surgery bone fixation materials, bone substitutes, and distractors. Childs Nerv Syst 2012;28(9): 1577-1588

108 Bhumiratana S, Vunjak-Novakovic G. Concise review: personalized human bone grafts for reconstructing head and face. Stem Cells Transl Med 2012;1(1):64-69

109 Mendonça JJ, Juiz-Lopez P. Regenerative facial reconstruction of terminal stage osteoradionecrosis and other advanced craniofacial diseases with adult cultured stem and progenitor cells. Plast Reconstr Surg 2010;126(5):1699-1709

110 Marx RE. Platelet-rich plasma: evidence to support its use. J Oral Maxillofac Surg 2004;62(4):489-496

111 Cao Y, Vacanti JP, Paige KT, Upton J, Vacanti CA. Transplantation of chondrocytes utilizing a polymer-cell construct to produce tissue-engineered cartilage in the shape of a human ear. Plast Reconstr Surg 1997;100(2):297-302, discussion 303-304

112 Friedman CD. Future directions in biomaterial implants and tissue engineering. Arch Facial Plast Surg 2001;3(2):136-137

113 Langhals NB, Urbanchek MG, Ray A, Brenner MJ. Update in facial nerve paralysis: tissue engineering and new technologies. Curr Opin Otolaryngol Head Neck Surg 2014;22(4):291-299

114 Ledgerwood LG, Tinling S, Senders C, Wong-Foy A, Prahlad H, Tollefson TT. Artificial muscle for reanimation of the paralyzed face: durability and biocompatibility in a gerbil model. Arch Facial Plast Surg 2012;14(6):413-418

115 Henstrom DK. Masseteric nerve use in facial reanimation. Curr Opin Otolaryngol Head Neck Surg 2014;22(4):284-290

116 Fisher MD, Zhang Y, Erdmann D, Marcus J. Dissection of the masseter branch of the trigeminal nerve for facial reanimation. Plast Reconstr Surg 2013;131(5):1065-1067

117 Yoshioka N, Tominaga S. Masseteric nerve transfer for short-term facial paralysis following skull base surgery. J Plast Reconstr Aesthet Surg 2015;68(6):764-770

118 Cooper TM, McMahon B, Lex C, Lenert JJ, Johnson PC. Cross-facial nerve grafting for facial reanimation: effect on normal hemiface motion. J Reconstr Microsurg 1996;12(2):99-103
119 Biglioli F. Facial reanimations: part I-recent paralyses. Br J Oral Maxillofac Surg 2015;53(10):901-906

120 Frey M, Michaelidou M, Tzou CH, Hold A, Pona I, Placheta E. Proven and innovative operative techniques for reanimation of the paralyzed face. Handchir Mikrochir Plast Chir 2010;42(2): 81-89

121 Hadlock T, Cheney ML. Facial reanimation: an invited review and commentary. Arch Facial Plast Surg 2008;10(6):413-417

122 Alam DS, Chi JJ. Facial transplantation for massive traumatic injuries. Otolaryngol Clin North Am 2013;46(5):883-901

123 Salibian AA, Widgerow AD, Abrouk M, Evans GR. Stem cells in plastic surgery: a review of current clinical and translational applications. Arch Plast Surg 2013;40(6):666-675

124 Matsumoto D, Sato K, Gonda K, et al. Cell-assisted lipotransfer: supportive use of human adipose-derived cells for soft tissue augmentation with lipoinjection. Tissue Eng 2006;12(12): 3375-3382

125 Eun S-C. Stem cell and research in plastic surgery. J Korean Med Sci 2014;29(Suppl 3):S167-S169

126 Francis MP, Sachs PC, Elmore LW, Holt SE. Isolating adiposederived mesenchymal stem cells from lipoaspirate blood and saline fraction. Organogenesis 2010;6(1):11-14

127 Balderson S, Caputo J, Colen B, Girard L, Hermann M. Stem cell tourism: false hope for real money. Stem Cell Lines 2013;8(1). Available at: http://hsci.harvard.edu/stem-cell-tourism. Accessed September 22, 2015

128 Hershcovitch MD, Hom DB. Update in wound healing in facial plastic surgery. Arch Facial Plast Surg 2012;14(6):387-393

129 Hom DB. New developments in wound healing relevant to facial plastic surgery. Arch Facial Plast Surg 2008;10(6):402-406

130 Trindade A, Djokovic D, Gigante J, et al. Low-dosage inhibition of Dll4 signaling promotes wound healing by inducing functional neo-angiogenesis. PLoS ONE 2012;7(1):e29863

131 Carter MJ, Fylling CP, Parnell LKS. Use of platelet rich plasma gel on wound healing: a systematic review and meta-analysis. Eplasty 2011;11:e38

132 Sclafani AP, McCormick SA. Induction of dermal collagenesis, angiogenesis, and adipogenesis in human skin by injection of platelet-rich fibrin matrix. Arch Facial Plast Surg 2012;14(2): 132-136

133 Qureshi AA, Ross KM, Ogawa R, Orgill DP. Shock wave therapy in wound healing. Plast Reconstr Surg 2011;128(6):721e-727e

134 Li Q, Kao H, Matros E, Peng C, Murphy GF, Guo L. Pulsed radiofrequency energy accelerates wound healing in diabetic mice. Plast Reconstr Surg 2011;127(6):2255-2262

135 Beanes SR, Dang C, Soo C, et al. Down-regulation of decorin, a transforming growth factor-beta modulator, is associated with scarless fetal wound healing. J Pediatr Surg 2001;36(11): 1666-1671

136 Beanes SR, Hu FY, Soo C, et al. Confocal microscopic analysis of scarless repair in the fetal rat: defining the transition. Plast Reconstr Surg 2002;109(1):160-170 